\title{
NEONATAL CHARACTERISTICS AND TEMPERAMENT PREDICT BEHAVIOR PROBLEMS IN CHILDREN BORN PRETERM
}

\author{
Vivian Caroline Klein ${ }^{1}$, Claudia Maria Gaspardoํㅜ, Francisco Eulógio Martinez², \\ Maria Beatriz Martins Linhares ${ }^{1}$
}

DOI: http://dx.doi.org/10.7322/jhgd.103750

\begin{abstract}
Introduction: the preterm birth is a risk factor for child developmental and behavioral problems. Objective: to examine whether neonatal clinical characteristics of infants born preterm, as well as temperament assessed in toddlerhood, predict behavior problems during the preschool years. Methods: twenty-one children born preterm with very low birth weight were assessed longitudinally at three different ages: in the neonatal period, during toddlerhood, and in preschool. Medical charts were reviewed to assess infants' clinical illness characteristics at the neonatal phase. Mothers fulfilled the Early Childhood Behavior Questionnaire for assessing temperament at the toddlerhood and the Child Behavior Checklist-1.5-5 for assessing children's behavior problems at the preschool age. Results: very low birth weight associated with child temperament at the toddlerhood predicted behavior problems at the preschool age. High levels of excitement about expected pleasurable activities as well as low levels of inhibitory control increased the chance of exhibiting externalizing behavior problems. Otherwise, high levels of both gross and fine motor activation increased the chance of exhibiting internalizing behavior problems. Conclusion: prematurity associated with temperament of poor self-regulation in developmental processes comprises a multiple-risk condition for clinical behavior problems in the preschool age.
\end{abstract}

Key words: prematurity, temperament, behavior.

\section{INTRODUCTION}

Preterm birth with very low birth weight is a relevant risk factor both biologically and psychosocially in child development ${ }^{1,2}$. Neonates are exposed to extra-uterine life before their physiological functions are mature enough to face the demands of the external environment. As part of the life-saving care in Neonatal Intensive Care Units (NICU), preterm and very low birth weight infants experience multiple stressors in the neonatal period, such as extended exposure to light and noise, acute and chronic illness, maternal separation, painful invasive procedures, excessive handling, and multiple medications ${ }^{3,4}$. These events occur during a sensitive and optimal time for brain development and neuronal differentiation ${ }^{5-7}$.

Children who are born preterm are more vulnerable to a range of problems related to cognition $^{8-10}$, attention $n^{8,9,11,12}$, learning ${ }^{10,11,13}$, and behavioral outcomes ${ }^{8,14}$. Specially, the assessments of the behaviors of children who are born preterm in comparison to children who are born full-term show the following main results: in toddlerhood, children who are born preterm exhibit more somatic complaints ${ }^{15}$, emotional symptoms, hyperactivity, conduct problems and peer relationship problems ${ }^{16}$; in the preschool years, children who are born preterm exhibit more withdrawn behaviors, thinking problems, somatic complaints, attention problems, delinquent behavior, aggressive behavior, social problems ${ }^{17}$, emotional problems, conduct problems, hyperactivity and peer relations problems ${ }^{14}$; during the school-aged years, children who are born preterm exhibit more somatic complaints, attention problems, hyperactivity and immature adaptive skills ${ }^{18}$. Otherwise, little is known about the etiology of these difficulties ${ }^{19}$.

Studies of preterm infants should focus on the complex mechanisms involved in the interplay between personal and environmental factors. Child temperament and self-regulation abilities, as well as the quality of family interactions and peer relationships, participate in transactional processes and are "key mechanisms" in the etiology of behavior problems $20-22$.

Self-regulation is a fundamental core domain of the major construct of temperament, according to Rothbart's psychobiological theoretical approach ${ }^{23}$. Temperament is a constitutionally based individual difference in reactivity and self-regulation mechanisms that appear early in life and are

\footnotetext{
1 Department of Neurosciences and Behavior, Ribeirão Preto Medical School, University of São Paulo, Ribeirão Preto, Brazil.

2 Department of Pediatrics, Ribeirão Preto Medical School, University of São Paulo, Ribeirão Preto, Brazil.

Corresponding author: Maria Beatriz Martins Linhares. E-mail: linhares@fmrp.usp.br
}

Suggested citation: Klein VC, Gaspardo CM, Martinez FE, Linhares MBM, Neonatal characteristics and temperament predict behavior problems in children born preterm. Journal of Human Growth and Development. 25(3): 331-340. Doi: http://dx.doi.org/10.7322/ jhgd. 103750

Manuscript submitted Sep 10 2015, accepted for publication Oct 072015. 
influenced over time by heredity, maturation, and experience ${ }^{24,25}$. Constitution refers to biologically based characteristic, with the individual's relatively enduring biological composition influenced over time by both genes and the environment. Reactivity refers to characteristics of the individual's responsivity to changes in stimulation shown at multiple levels (e.g., behavioral, autonomic, neuroendocrine) and through the parameters of latency, rise time, peak intensity, and recovery time. Self-regulation refers to processes modulating this reactivity, including approach, avoidance, inhibition, and attentional self-regulation ${ }^{26,27}$.

The structure of temperament includes the following three main factors: Negative affectivity, Surgency, and Effortful control ${ }^{28}$. In the Negative affectivity factor, the newborns shows relatively undifferentiated distress, but later it is possible to differentiate anger/frustration from fear. Infants expressed frustration by banging on the table or barrier and showing distress. They expressed fear by showing distress along with motor inhibition or withdrawal from a threatening object. Additionally, the Surgency temperament factor combines a disposition toward the positive emotions, rapid approach to potential rewards, and high activity level in a construct very similar to, and in adults, positively related to the personality factor of extraversion. Finally, voluntary attentional focusing, inhibitory control, perceptual sensitivity, and low-intensity pleasure dimensions compose the Effortful control factor, which emerge at preschool age and develop throughout school age and early adolescent phases.

The preterm infants present poor physiological, emotional, attentional, and behavioral regulation, from the neonatal phase through the preschool years ${ }^{29}$. Additionally, the study of Klein et al. ${ }^{30}$ showed that preterm neonates' biobehavioral reactivity-regulation responses during a painful procedure (e.g. puncture for blood collection) in NICU predict temperament profiles later in toddlerhood.

To better understand the development of the regulation process of preterm infants, one must take into account the relationship of prematurity and child temperament with later behavioral outcomes. Our hypothesis is that increased risk factors in the neonatal phase of infants who are born preterm associated with temperamental traits with higher negative affectivity and surgency, and lower effortful control on toddlerhood would predict later behavior externalizing and internalizing problems during the preschool years of age.

The aim of the present study was to examine longitudinally whether neonatal characteristics of infants who are born preterm and very low birth weight, as well as temperament assessed in toddlerhood, affect the self-regulation process, predicting later behavior problems during the preschool years.

\section{METHODS}

\section{Participants}

The sample was composed of 21 children who were born preterm ( $<37$ weeks of gestational age) and with very low birth weight ( $<1,500$ grams), who were assessed longitudinally at different three time points: as infants, toddlers, and preschoolers. Preterm infants were recruited from the NICU at a tertiary teaching hospital in an interior city in the southwest of a developing country. Neonates who had major congenital anomalies, and intraventricular hemorrhage (grade III/IV) were excluded. These children were subsequently followed longitudinally until preschool.

Forty-four preterm and very low birth weight neonates were recruited and assessed during the neonatal period. Due to health complications, five infants died during the neonatal period, and one additional participant died at toddlerhood. Of the 38 toddlers remaining, eight moved to live in other cities and could not be found, one mother had lost legal custody of her child, one mother was in a rehabilitation clinic for drug addiction, and two mothers did not consent to continue participating in the study. Thus, 26 children were assessed at toddlerhood, which represents $68 \%$ of the original eligible sample. Later, of these 26 children, five could not be found for assessment at the preschool age; the loss of the eligible sample in this phase was $19 \%$.

The final sample of the study was composed of 21 children (13 boys) who were assessed in the neonatal, toddler (mean chronological age $=26$ months; SD \pm 3.8 ; range 18 - 32), and preschool phases (mean chronological age $=42$ months; $\mathrm{SD} \pm 4.7$; range $37-50$ ).

\section{Ethical Procedures}

The study was approved by the Clinical Research Ethics Board of the hospital, and informed consent was obtained in all phases of the study.

\section{Setting}

Assessments at the neonatal phase were conducted in the NICU setting, and assessments at the toddler and preschool age were completed at the Follow-up of Premature Infants Program in the hospital.

\section{Measures and Procedures}

Neonatal Assessments. Prospective review of medical charts was performed independently by expert and trained physicians for collection of the following data: (a) infant characteristics, such as gestational age at birth, birth weight, and Apgar score at fifth-minute of post-natal age; (b) neonatal illness severity, which was estimated by computing the Clinical Risk Index for Babies (CRIB) score ${ }^{31}$. The CRIB was developed to predict the risk of mortality and morbidity in neonates based on birth weight, gestational age, presence or absence of congenital malformations, worst base excess and minimum and maximum appropriate fraction of inspired oxygen during the first 12 hours of postnatal age; (c) amount of pain exposure during NICU stay, computed as the number of invasive painful procedures as obtained through prospective review of medical charts performed independently by physician researchers who were blind to all of the neonate's other characteristics. The frequency of 
exposure to the following procedures from birth to discharge from the NICU was summed from the following items: venipuncture, arterial puncture, heel-lance, intravenous cannulation, endotracheal tube introduction, endotracheal tube suctioning, and gavage insertion for feeding. These acute painful procedures were selected based on the procedures included in the study by Johnston et al. ${ }^{32}$.

Toddlerhood Assessments. When the children were between 18 and 32 months of age, the mothers were invited to participate by phone or mail, or at medical appointments in the Pediatrics Clinic of the hospital. The child's temperament and the socioeconomic status of the family were assessed using the mother's report. Data collection was performed in an individual interview by an expert researcher who was blind to the child's neonatal health history. Mothers were interviewed using The Early Childhood Behavior Questionnaire - ECBQ ${ }^{33}$, Brazilian version by Klein and Linhares (http://www.bowdoin.edu/ sputnam/rothbarttemperament-questionnaires/instrumentdescriptions/early-childhood-behavior.html), for assessment of child temperament. This instrument is composed of 201 items that assess 18 dimensions of temperament in children between the ages of 18 and 36 months. Factor analysis revealed a threefactor structure of Negative Affectivity, including six scales (Soothability Negatively Loaded, Frustration, Discomfort, Motor Activation, Fear, Sadness), Surgency, including seven scales (Sociability, Activity level, Impulsivity, Positive Anticipation and High Intensity Pleasure), and Effortful Control, including five scales (Low Intensity Pleasure, Attention Shifting, Attention Focusing, Inhibitory Control and Cuddliness). Parents were asked to rate the frequency of specific temperament-related behaviors observed over the past two weeks in an ordinal scale ranging from 1 ("never") to 7 ("always"). Putnam et al. ${ }^{33}$ reported internal consistency of these scales ranging from 0.57 to 0.90 (standard $\alpha=0.81$ ) and inter-rater agreement ranging from 0.09 to .57 (average $r=0.39$ ). The internal consistency of the scales in a Brazilian sample, which included the sample of the present study, ranged from 0.43 to 0.88 (average $\alpha=0.72)^{34}$. Additionally, the mothers completed the Brazilian Criteria for Economic Classification- Brazilian Association of Research Companies (CCEB-ABEP), for the socioeconomic status assessment ${ }^{35}$. This questionnaire included items such as family income, parents' educational level, number of people living in the same house, and number of cars, refrigerators, and televisions per family. This tool provides a score to characterize the socioeconomic status of the families.

Preschool Assessments. When the children were between 37 and 50 months of age, behavior problems were assessed by the mothers' report at the preschool age. Mothers were interviewed through The Child Behavior Checklist for Ages 1.5-5 - CBCL 1.5-536, using the Brazilian version by Linhares, Santa Maria-Mengel, Silvares, and Rocha. The CBCL is a child behavior checklist that utilizes parents' reports and is appropriate for children between 18 months and 5 years old.
The respondent is asked to rate 99 problem items about the child as " 0 " (zero) for "not true," " 1 " for "somewhat or sometimes true," and " 2 " for "very true or often true," based on the preceding two months. Item scores are summed and then converted to normalize T- scores ${ }^{36}$. Higher scores represent more deviant behavior. The CBCL consists of seven Syndrome Scale Scores for boys and girls, which are grouped into two broad Syndromes: 1) Internalizing, including Emotionally Reactive, Anxious/Depressed, Somatic Complaints, and Withdrawn; 2) Externalizing, including Attention Problems and Aggressive Behavior. The syndrome scale Sleep Problems is analyzed independently. The T-scores $\leq 65$ fit in the Normal classification, scores between 65 and $70 \mathrm{fit}$ in the Borderline classification, and scores $>70$ fit in the Clinical classification.

\section{Statistical treatment}

The Statistical Package for the Social Sciences (SPSS, version 19.0, Chicago, IL, USA) was used for data analysis. The statistical treatment followed four steps: (1) the Kolmogorov-Smirnov test was used to examine the normality of the variable distributions; (2) considering that the variables exhibited normal distribution, we calculated Pearson's Correlation Coefficient between neonatal characteristics, temperament at toddlerhood and behavior problems at the preschool age; (3) the multicolinearity between neonatal characteristics and temperament assessed at toddlerhood was tested; (4) linear regression analyses were conducted to examine whether the neonatal characteristics and temperament at toddlerhood predicted behavior problems at the preschool age (predictive variable). In each regression model, considering the number of participants, we tested the maximum amount of four predictors for each predictive behavior problem variable. Only the predictor variables that presented statistically significant correlations with the predictive variables were included in the regression models. The statistical significance level for all the tests in the present study was set at $\mathrm{p} \leq 0.05$.

\section{RESULTS}

The characteristics of the participants are presented in Table 1.

As seen in Table 1, the neonates were born very preterm, with a mean gestational age of 30 weeks at birth and an average birth weight of 1,062 grams. The Apgar at $5^{\text {th }}$ minute and the CRIB score revealed favorable prognosis for clinical progress. The time spent in the NICU was one month on average, and length of total hospital stay was approximately two months on average. The infants were exposed to an average of 96 painful procedures during hospitalization in the NICU and 106 painful procedures during their total hospital stay; thus, most of the painful procedures occurred during the NICU period. The majority of the families were of low socioeconomic status based on parents' education level and family's annual income. 
Table 1: Characteristics of the sample

\section{Characteristics of the children and their families}

Children at neonatal phase - M (SD)

Birth weight (grams)

Gestational age (weeks)

Apgar at $5^{\text {th }}$ min (score)

Clinical Risk Index for Babies (score)

229)

$30( \pm 1.8)$

Duration of mechanical ventilation (days)

$8( \pm 1.8)$

$4( \pm 3.2)$

Time stay in NICU (days)

Time stay in hospital (days)

Number of painful procedures in NICU

$3.6( \pm 2)$

$26( \pm 18)$

$60( \pm 16)$

$96( \pm 93)$

Number of painful procedures in the hospital stay

\section{Family characteristics}

Mothers' age at delivery (years) - M (SD)

$29( \pm 8)$

Mothers' schooling (years) - M (SD)

$7( \pm 3.7)$

Fathers' schooling (years) - M (SD)

$7( \pm 3.6)$

Socio-economic status (CCEB-ABEP) - Frequency (\%)

Level C

$14(65)$

Level D

Level B

Marital status - Frequency (\%)

Married/ Cohabitating

$14(66)$

Single

$7(34)$

Note: CCEB-ABEP = Brazilian Criteria for Economic Classification- Brazilian Association of Research Companies; NICU = Neonatal Intensive Care Unit; $\mathrm{M}=$ Mean; SD = Standard Deviation.

Table 2: Temperament factors and dimensions of children at toddlerhood

$\begin{array}{lc}\text { Temperament Factors and Dimensions (ECBQ) } & \text { M (SD) } \\ \text { Negative Affectivity } & 3.3( \pm 0.7) \\ \text { Soothability } & 4.3( \pm 0.3) \\ \text { Frustration } & 3.8( \pm 1.2) \\ \text { Discomfort } & 3.3( \pm 0.9) \\ \text { Motor Activation } & 3.0( \pm 1.0) \\ \text { Fear } & 3.0( \pm 1.3) \\ \text { Sadness } & 2.8( \pm 1.0) \\ \text { Shyness } & 3.0( \pm 1.5) \\ \text { Perceptual Sensitivity } & 6.0( \pm 1.0) \\ \text { Surgency } & 5.5( \pm 0.5) \\ \text { Sociability } & 6.0( \pm 1.2) \\ \text { Activity level } & 5.6( \pm 0.9) \\ \text { Impulsivity } & 5.5( \pm 0.8) \\ \text { Positive Anticipation } & 5.3( \pm 1.2) \\ \text { High Intensity Pleasure } & 5( \pm 1.1) \\ \text { Effortful Control } & 4.4( \pm 0.7) \\ \text { Low Intensity Pleasure } & 5.4( \pm 0.8) \\ \text { Attention Shifting } & 5.3( \pm 1.1) \\ \text { Cuddliness } & 4.7( \pm 1.4) \\ \text { Attention Focusing } & 3.5( \pm 1.2) \\ \text { Inhibitory Control } & 3.3( \pm 1.6)\end{array}$

Note: $\mathrm{ECBQ}=$ The Early Childhood Behavior Questionnaire, range scores from 1 to 7 ; $M=$ Mean; SD = Standard Deviation.

\section{Temperament at toddlerhood}

As shown in Table 2, the temperament assessment in toddlerhood showed that the children who were born preterm presented high average scores $(\geq 5)$ on the Surgency factor and its dimensions (Sociability, Activity Level, Impulsivity, Positive Anticipation, and High Intensity Pleasure) and on Low Intensity Pleasure, Attention Shifting, and Perceptual Sensitivity. No statistically significant correlations between the ECBQ temperament scores and chronological age of the toddlers were found.

\section{Behavior problems at the preschool age}

Table 3 shows that, according to the mothers' reports, the children who were born preterm exhibited high T-scores in the internalizing syndromes axis at the preschool age. Thirty-three per cent of children were classified as scoring within the clinical range. Regarding the internalizing axis, 
Table 3: Behavioral outcomes of children at the preschool age

$\begin{array}{lcc}\text { Behavior Problems } & \text { T- Score } & \text { Clinical Classification } \\ \text { (CBCL 1.5-5) } & \text { M (SD) } & 27 \\ \text { Total Problems } & 56( \pm 11) & 27 \\ \text { Externalizing Problems } \quad \text { Aggressive Behavior } & 54( \pm 12) & 10 \\ \quad \text { Attention Problems } & 57( \pm 9) & 12 \\ \text { Internalizing Problems } \quad 58( \pm 8) & 33 \\ \quad \text { Anxious/Depressed } \quad \text { Emotionally Reactive } & 57( \pm 10) & 21 \\ \quad \text { Withdrawn } & 59( \pm 8) & 6 \\ \quad \text { Somatic Complaints } & 56( \pm 7) & 9 \\ \text { Sleep Problems } & 56( \pm 8) & 15\end{array}$

Note: $\mathrm{CBCL} 1 \frac{1}{2}-5$ = The Child Behavior Checklist; T-score classifications, $\leq 65=$ Normal; T- score $>65$ e $\leq 70=$ Borderline; $\mathrm{T}$ - score $>70=$ Clinical; $\mathrm{M}=$ Mean; $\mathrm{SD}=$ Standard Deviation .

Anxious/Depressed and Somatic Complaints were the syndrome scales with higher scores. However, concerning the Externalizing axis, $27 \%$ of children were in the clinical score range. Attention Problems was the syndrome scale with the highest score, with $12 \%$ of children falling within the clinical range.

\section{Neonatal characteristics and temperament at the toddlerhood as predictors of behavior problems at the preschool age}

Two sets of variables were included as predictor variables of behavior problems of children at the preschool age, as follows: (1) neonatal characteristics (gestational age, birth weight, neonatal clinical severity of illness, and the number

Table 4: Predictive models of behavior outcomes of children at the preschool age (CBCL $1 \frac{1 / 2}{2}-5$ T- Scores, Total Problems, Externalizing, and Internalizing)

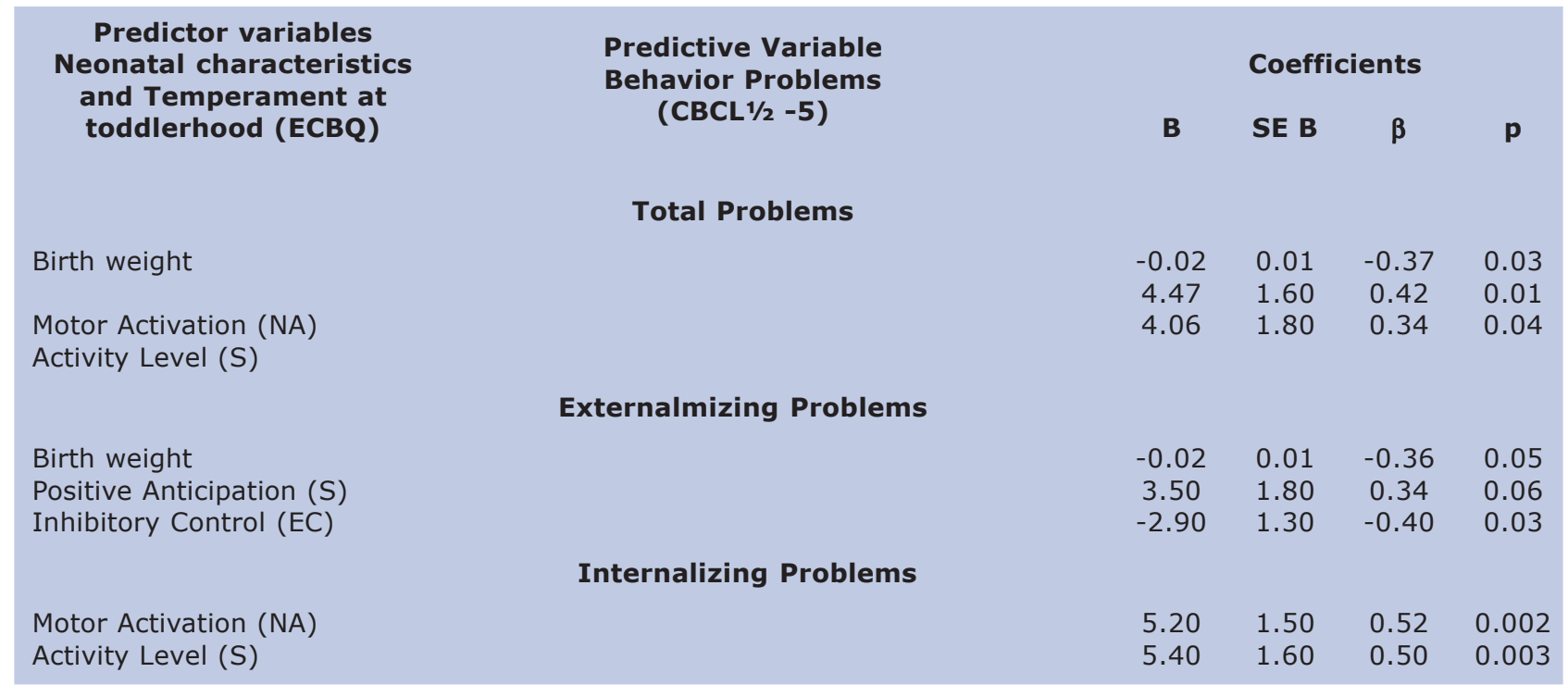

Note: $R^{2}=$ variance; $B=$ Coefficient of Regression; $S E B=$ Standard error; $\beta=$ Standard Coefficient of Regression; $\mathrm{NA}=$ Negative Affectivity; $\mathrm{S}=$ Surgency; $\mathrm{EC}=$ Effortful Control.

of painful procedures in the NICU); (2) the temperament factors and dimensions assessed at toddlerhood.

As shown in Table 4, lower birth weight $(\beta=-0.37 ; p=0.03)$ and higher scores of motor activation $(\beta=0.42 ; p=0.01)$ and activity level $(\beta=0.34 ; p=0.04)$ at toddlerhood predicted higher scores in the CBCL total problems at the preschool age, accounting for $58 \%$ of the variance $(p=0.0001)$. The sociability and positive anticipation temperament dimensions were excluded from the model because they did not increase the statistical significance of the model.
Lower birth weight $(\beta=-0.36 ; p=0.05)$, lower scores of inhibitory control $(\beta=-0.40 ; p=0.03)$, and higher scores of positive anticipation $(\beta=0.34$; $p=0.06$ ) at toddlerhood predicted higher scores in externalizing problems at the preschool age. This model accounted for $45 \%$ of the variance in the predictive variable $(p=0.004)$. The activity level temperament dimension was excluded from the model because it did not increase the statistical significance of the model. Otherwise, higher scores in motor activation $(\beta=0.52 ; p=0.002)$ and activity level $(\beta=0.50 ; p=0.003)$ at toddlerhood predicted higher scores in internalizing behavior problems at the 
Table 5: Predictive models of behavior outcomes of children at the preschool age (CBCL $11 / 2-5$ T Scores, Attention Problems, Aggressive Behavior, Emotionally Reactive, Anxious/ Depressed, Withdrawn, Somatic Complaints, and Sleep Problems Syndromes)

\begin{tabular}{|c|c|c|c|c|c|}
\hline \multirow{2}{*}{$\begin{array}{l}\text { Predictor variables } \\
\text { Neonatal characteristics } \\
\text { and Temperament at } \\
\text { toddlerhood (ECBQ) }\end{array}$} & \multirow{2}{*}{$\begin{array}{l}\text { Predictive Variable } \\
\text { Behavior Problems } \\
\text { (CBCL1/2 -5 Syndromes) }\end{array}$} & \multicolumn{4}{|c|}{ Coefficients } \\
\hline & & B & SE B & $\beta$ & $\mathbf{p}$ \\
\hline & Attention Problems & & & & \\
\hline Birth weight & & -0.02 & 0.01 & -0.51 & 0.009 \\
\hline Activity Level (S) & & 3.30 & 1.60 & 0.36 & 0.05 \\
\hline & Aggressive behavior & & & & \\
\hline Positive Anticipation (S) & & 3.80 & 1.20 & 0.52 & 0.006 \\
\hline Sociability (S) & & -3.10 & 1.60 & -0.44 & 0.02 \\
\hline & Emotionally Reactive & & & & \\
\hline Birth weight & & -0.02 & 0.01 & -0.61 & 0.001 \\
\hline Impulsivity (S) & & -4.20 & 1.30 & -0.49 & 0.005 \\
\hline & Anxious/ Depressed & & & & \\
\hline Motor Activation (NA) & & 3.30 & 1.55 & 0.42 & 0.05 \\
\hline Positive Anticipation (S) & & 2.41 & 1.30 & 0.37 & 0.08 \\
\hline & Somatic Complaints & & & & \\
\hline Motor Activation (NA) & & 3.25 & 1.64 & 0.39 & 0.06 \\
\hline Cuddliness (EC) & & -2.20 & 1.13 & -0.37 & 0.07 \\
\hline & Withdrawn & & & & \\
\hline Activity Level (S) & & 3.70 & 1.51 & 0.44 & 0.02 \\
\hline Sociability (S) & & -2.75 & 1.09 & -0.45 & 0.02 \\
\hline & Sleep Problems & & & & \\
\hline Birth weight & & -0.01 & 0.05 & -0.37 & 0.03 \\
\hline Sociability (S) & & -3.80 & 0.98 & -0.59 & 0.001 \\
\hline
\end{tabular}

Note: $\mathrm{R} 2$ = variance; $B=$ Coefficient of Regression; SE B = Standard error; $\beta=$ Standard Coefficient of Regression; $N A=$ Negative Affect; $S=$ Surgency; $E C=$ Effortful Control.

preschool age, accounting for $58 \%$ of the variance in the predictive variable $(p=0.0001)$. The birth weight variable was excluded from the model because it did not increase the statistical significance of the model.

As shown in Table 5, lower birth weight $(\beta=-0.51 ; p=0.009)$ and higher scores on the temperament dimension of activity level $(\beta=0.36$; $\mathrm{p}=0.05$ ) at toddlerhood specifically predicted higher scores in attention problems at the preschool age, accounting for $44 \%$ of the variance $(p \geq 0.002)$. The temperament dimensions of positive anticipation and motor activation were excluded from the model because they did not increase the statistical significance of the model.

Higher scores on the temperament dimension of positive anticipation ( $\beta=0.52 ; p=0.006)$ and lower scores in sociability $(\beta=-0.44 ; p=0.02)$ were predictors of higher scores in aggressive behavior. This model accounted for $46 \%$ of the observed variance $(p=0.002)$. Moreover, lower birth weight $(\beta=-0.61 ; p=0.001)$ and lower scores in impulsivity $(\beta=-0.42 ; p=0.005)$ at toddlerhood were predictors of higher scores in emotionally reactivity at the preschool age, accounting for $54 \%$ of the variance $(p=0.0001)$. Neonatal clinical illness risk was excluded from the model because it did not increase the statistical significance of the model.

Higher scores in motor activation $(\beta=0.42$; $\mathrm{p}=0.05)$ and positive anticipation $(\beta=0.37$; $\mathrm{p}=0.08$ ) at toddlerhood predicted higher scores in anxious/depressed symptoms at the preschool age. This model accounted for $38 \%$ of the variance $(p=0.005)$. Higher scores in motor activation $(\beta=0.39 ; p=0.06)$ and lower scores in cuddliness $(\beta=-0.37 ; p=0.07)$ predicted higher scores in somatic complaints. This set of variables explained $26 \%$ of the variance ( $p=0.02)$.

Higher scores in activity level $(\beta=0.44$; $\mathrm{p}=0.02$ ) and lower scores in sociability $(\beta=-0.45 ; p=0.02)$ predicted higher T-scores in withdrawn behavior, accounting for $35 \%$ of the variance $(p=0.008)$. The sleep problems were predicted by low birth weight $(\beta=-0.37 ; p=0.03)$ and low scores in sociability in toddlerhood ( $\beta=-0.59 ; p=0.001)$. Altogether, these variables explained $60 \%$ of the observed variance in sleep problems at the preschool age $(p=0.0001)$. Neonatal clinical illness risk (CRIB score), fear, negative affectivity and motor activation were excluded from the model because they did not increase the statistical significance of the model.

\section{DISCUSSION}

To our knowledge, the current study is the first to address whether characteristics of the neonatal phase of preterm and low birth weight infants that are associated with temperament at toddlerhood have a later impact on children's behavior during the preschool years. Our findings showed that both neonatal characteristics and temperament in toddlerhood influence the pathway of behavior problems in this sample of children born preterm at preschool age. Focusing on the impact of the neonatal characteristics in the prediction of behavior problems, we found that birth weight accounted for behavior problems at the preschool age. Neonates with lower birth weight, who consequently had higher clinical illness severity, 
were more likely to exhibit externalizing problems, specifically attention problems, such as being impulsive and difficulty concentrating and sitting still. Lower birth weight also predicted internalizing problems related to emotional reactivity. The predictive correlations above were statistically significant independent of the toddler's temperament, which evidence the specific impact of birth weight on behavior problems.

In the current study, the prediction models that combined birth weight and specific dimensions of temperament assessed at toddlerhood enhanced the power of explanation of behavior problems at the preschool age. We found that lower birth weight associated with less impulsive temperament was predictive of emotional reactivity problems at the preschool age. Lower birth weight and less impulsive temperament may be related to withdrawn behaviors, isolation, fear and sadness, which may consequently, leads children to exhibit emotional problems.

Our data also showed that lower birth weight in combination with higher activity levels and motor activation was a predictor of higher total scores in behavior problems at the preschool age. Moreover, lower birth weight and temperament characterized by higher activity levels were predictors of attention problems. These findings are consistent with the findings of $\mathrm{Blai}^{37}$ regarding the predictive correlations between high activity level temperaments and externalizing behaviors in preterm toddlers.

We found that lower birth weight combined with lower inhibitory control and higher positive anticipation was predictive of externalizing problems. The temperament dimension of inhibitory control is included in the effortful control temperament factor, which is related to one of the most sophisticated components of self-regulation, cognitive or executive self-regulation ${ }^{38,39}$. According to Muris and Ollendick ${ }^{40}$, the relationship between the temperament dimension of inhibitory control and externalizing behavioral problems has been observed at different ages. The temperament dimension of positive anticipation is related to approach and surgency. In our study, children with lower birth weight, higher levels of enthusiasm and anticipation facing expected events and lower ability to inhibit or moderate behavior according to external demands were more likely to have externalizing problems. These findings are consistent with the findings of Gunnar et al. ${ }^{41}$ regarding the association between higher levels of surgency and lower levels of effortful control in the prediction of higher levels of aggression with peers and peer rejection during the preschool years. Accordingly, the role of the surgency factor in the interplay between risk and protective factors in the children's developmental pathway is related to their level of selfregulation. According to Olson et al. ${ }^{21}$, children with high levels of surgency and high levels of selfregulation are more likely to exhibit good social competency, while children with high levels of surgency and low levels of self-regulation are more likely to exhibit externalizing behavior problems. We might hypothesize that the level of developmental self-regulation moderates the effect of a temperament with high surgency on a child's behavior.
The findings of the present study showed that at the toddlerhood, a temperament with lower levels of sociability in combination with higher levels of positive anticipation facing expected events was predictive of aggressive behavior in children born preterm at preschool age. The temperament with low levels of seeking and taking pleasure in interactions with others and with high excitement about expected pleasurable activities increased the risk of presenting aggressive behaviors, such as arguing, being cruel to others, destroying others' property and fighting. Moreover, our data showed that low levels of sociability associated with high levels of motor activation at toddlerhood accounted for increased withdrawn behaviors, such as preferring to be alone, refusing to talk and being shy. The temperament dimension of sociability is an important variable in the interplay of risk factors and protection mechanisms in the child development pathway. According to Wachs ${ }^{42}$, in a group of children at risk, lower behavior problems, better cognitive performance, and social competency were found in children who had temperament with high levels of sociability.

Our findings also showed that a temperament with a high level of motor activation, including repetitive fine motor movements and fidgeting, and with a high level of gross-motor activation was predictive of internalizing behavior problems, specifically those related to anxiety and depression, such as feeling guilty, nervous and preoccupied. Moreover, a temperament with a high level of fine motor activation in combination with a low level of cuddliness was predictive in the preschool age of somatic complaints, such as complaining about fatigue, pain, nausea, and eye problems. In the current study that correlate fine motor activation with internalizing problems are consistent with the findings on toddlers born full-term ${ }^{43}$ and on adults ${ }^{44}$. Additionally, the fine motor activity was associated with depressive symptoms ${ }^{44}$.

The set of findings in the present study reveals that low birth weight is a risk factor for both temperament and behavioral vulnerabilities. It is associated to other adverse factors ${ }^{1}$, such as high clinical severity, extended time in the NICU, prolonged exposure to pain, and early mother-infant separation, thus representing a biological and psychosocial risk for psychopathology3.

In conclusion, our findings demonstrate poor self-regulation of behavioral processes, similar to previous findings ${ }^{29}$, adding the contribution to this processes of temperament dispositional traits. The high neonatal biological risk, when associated with individual characteristics, such as temperament with high levels of both gross and fine motor activation, high excitement about expected pleasurable activities and low inhibitory control, increases the likelihood for the child to exhibit both externalizing and internalizing behavior problems. To our knowledge, this is the first study to address the combined impact of both neonatal characteristics and temperament assessed at toddlerhood through Rothbart's psychobiological approach on behavior problems of preschool children born preterm. The results from this study contribute to a betterdeveloped framework for understanding the 
developmental outcomes of children who are born preterm, suggesting that premature birth and specific temperament characteristics may impact children's behavior and developmental selfregulation.

The present study has some limitations: a) It did not include an assessment of parent-child interaction and its relationships to neonatal characteristics, child temperament and behavior problems. The quality of the child-family and childpeer interactions is fundamental for enhancing comprehension of child development, since its outcomes occur through transactional and interpersonal processes ${ }^{21,45}$. Transactional processes that relate parent-child interactions with self-regulation are considered key mechanisms for understanding the genesis of behavior problems ${ }^{21}$; b) The study had a small sample size. Nevertheless, our results regarding neonatal characteristics and behavior problems were consistent with those in the literature and provide novel results concerning previously unstudied aspects of temperament and its relationship to behavior. In addition, the findings of this sample presents an ecological validity regarding that they represent the typical children supported in NICU settings at neonatal phase. Replication with larger samples will be beneficial in evaluating the generalization of our results; c) Children's temperament and behavior were assessed through only one informant. Despite concerns over rater bias, substantial objective validity of parent-report measures of temperament has been supported ${ }^{46,47}$. Parental report allows for measurement of individual differences both broadly and narrowly, taking advantage of the caregiver's extensive amount of observation ${ }^{46}$ and the ability of parents to observe their children in a wide range of situations that are ethically and logistically impossible to recreate in the laboratory ${ }^{48}$.

\section{REFERENCES}

1. Aylward GP. Methodological issues in outcome studies of at-risk infants. J Pediatr Psychol. 2002;27(1):37-45. DOI: http://dx.doi.org/ 10.1093/jpepsy/27.1.37.

2. Minde K. Prematurity and serious medical conditions in infancy: implications for development, behavior and intervention. In: Zeanah C. Handbook of Infant Mental Health. New York: The Guilford Press; 2000; p. 176-94.

3. Grunau RE, Holsti L, Peters JWB. Long-term consequences of pain in human neonates. Semin Fetal Neonatal Med. 2006;11(4): 268-75. DOI: http://dx.doi.org/10.1016/j.siny. 2006.02.007.

4. Valeri BO, Holsti L, Linhares MB. Neonatal pain and developmental outcomes in children born preterm A systematic review. Clin J Pain. 2015;31(4):355-62. DOI: http://dx.doi.org/ 10.1097/AJP.0000000000000114.

5. Couperus JW, Nelson, CA. Early brain development and plasticity. In: McCartney K, Phillips D. Blackwell handbook of early childhood development. Malden: Blackwell Publishing; 2006; p.85-105.
Nonetheless, the results from this study contribute to a better-developed framework for understanding the developmental outcomes of children who are born preterm. The results also have relevant clinical practical implications for this population. Developmental care strategies should be implemented in NICU settings for very early biobehavioral regulation of tiny neonates, as proposed by $\mathrm{Als}^{49}$. Moreover, follow-up programs should be offered post-discharge to support caregivers in helping children who are born preterm to achieve emotional and behavior self-regulation in the developmental pathway.

Future studies could include observational techniques for assessing children's temperament and behavior and to expanding our knowledge about the relationship between these two constructs in premature birth children. In addition, these studies could explore the relationships between neonatal characteristics, parent-child interaction patterns and children's temperament for predicting children's behavior problems.

\section{Acknowledgements}

The authors gratefully thank the financial support of The State of São Paulo Research Foundation (FAPESP, Brazil grant \#05/56200-1) and of The Pain in Child Health Training Consortium (PICH, Canada) to Vivian C. Klein, The Improvement of Higher Education Level (CAPES - Brazil) to Claudia M. Gaspardo, and The National Council for Scientific and Technological Development (CNPq - Brazil) to Maria Beatriz M. Linhares. The authors also thank the Neonatology Service at the Hospital of Clinics of the Ribeirão Preto Medical School, University of São Paulo, and the families for participating in this study.

6. Ranger M, Grunau RE. Early repetitive pain in preterm infants in relation to the developing brain. Pain Manag. 2014;4(1):57-67. DOI: http://dx.doi.org/10.2217/pmt. 13.61.

7. Vinall J, Grunau RE. Impact of repeated procedural pain-related stress in infants born very preterm. Pediatr Res. 2014;75(5):584-7. DOI: http://dx.doi.org/10.1038/pr. 2014.16.

8. Johnson S. Cognitive and behavioural outcomes following very preterm birth. Semin Fetal Neonatal Med. 2007;12(5):363-73. DOI: http:/ /dx.doi.org/10.1016/j.siny.2007.05.004.

9. Luu TM, Ment LR, Schneider KC, Katz KH, Allan WC, Vohr BR. Lasting effects of preterm birth and neonatal brain hemorrhage at 12 years of age. Pediatrics. 2009;123(3):1037-44. DOI: http://dx.doi.org/10.1542/peds.2008-1162.

10. Wolke D, Samara M, Bracewell M, Marlow N; EPICure Study Group. Specific language difficulties and school achievement in children born at 25 weeks of gestation or less. J Pediatric. 2008;152(2):256-62. DOI: http:// dx.doi.org/10.1016/j.jpeds.2007.06.043.

11. Salt A, Redshaw M. Neurodevelopmental followup after preterm birth: follow up after two years. Early Hum Dev. 2006;82(3):185-97. 
DOI: http://dx.doi.org/10.1016/j.earlhumdev. 2005.12.015.

12. Weijer-Bergsma EV, Wijnroks L, Jongmans MJ. Attention development in infants and preschool children born preterm: a review. Infant Behav Dev. 2008;31(3):333-51. DOI: http://dx.doi. org/10.1016/j.infbeh.2007.12.003.

13. Whitfield M, Grunau RE. Behavior, pain perception, and the extremely low-birth weight survivor. Clin Perinatol. 2000; 27(2): 363-79.

14. Samara M, Marlow N, Wolke D; The Epicure Study Group. Pervasive behavior problems at 6 years of age in a total-population sample of children born at $<25$ weeks of gestation. Pediatrics. 2008;122(3):562-73. DOI: http:// dx.doi.org/10.1542/peds.2007-3231.

15. Stoelhorst GMSJ, Martens SE, Rijken M, Van Zwieten PHT, Zwinderman AH, Wit JM, et al. Behavior at two years of age in very preterm infants (gestational age $<32$ weeks). Acta Paediatr. 2003; 92(5): 595-601. DOI: http:// dx.doi.org/10.1111/j.1651-2227.2003. tb 02513.x.

16. Delobel-Ayoub M, Kaminski M, Marret S, Burguet A, Marchand L, Guyen $S N$, et al. Behavioral outcome at three years of age in very preterm infants: the Epipage Study. Pediatrics. 2006;117(6):1996-2005. DOI: http://dx.doi.org/10.1542/peds.2005-2310.

17. Reijneveld SA, Kleine MJK, Van Baar, AL, Kollée LAA, Verhaak CM, Verhulst FC, et al. Behavioural and emotional problems in very preterm and very low birthweight infants at age 5 years. Arch Dis Child Fetal Neonatal Ed. 2006; 91(6): 423-8. DOI: http://dx.doi.org/10.1136/adc. 2006.093674.

18. Anderson PJ, Doyle LW, Victorian Infant Collaborative Study Group. Neurobehavioral outcomes of school-age children born extremely low birth weight or very preterm in the 1990s. JAMA. 2003; 289(24): 3264-72. DOI: http:// dx.doi.org/10.1001/jama.289.24.3264.

19. Tu MT, Grunau RE, Petrie-Thomas J, Haley DW, Weinberg J, Whitfield MF, et al. Maternal stress and behavior modulate relationships between neonatal stress, attention, and basal cortisol at eight months in preterm infants. Dev Psychobiol. 2007; 49(2): 150-64. DOI: http:// dx.doi.org/10.1002/dev.20204.

20. Eisenberg N, Smith CL, Spinrad TL. Effortful Control. In: Vohs KD, Baumeister RF. Handbook of self-regulation: research, theory and applications. New York: The Guilford Press; 2011; p. 263-83.

21. Olson SI, Sameroff A, Lunkenheimer ES, Kerr D. Self-regulatory processes in the development of disruptive behavior problems: the pre-school to school transition. In: Olson SL, Sameroff AJ. Biopsychosocial regulatory processes in the development of childhood behavioral problems. New York: Cambridge University Press; 2009; p. 144-85.

22. Sameroff AJ. Conceptual issues in studying the development of self-regulation. In: Olson SL, Sameroff AJ. Biopsychosocial regulatory processes in the development of childhood behavioral problems. New York: Cambridge University Press; 2009; p. 1-18.

23. Goldsmith $\mathrm{HH}$, Buss $A \mathrm{H}$, Plomin R, Rothbart MK, Thomas A, Chess S, et al. Roundtable: what is temperament? Four approaches. Child Dev. 1987;58(2):505-29. DOI: http://dx.doi.org/ $10.2307 / 1130527$.

24. Cosentino-Rocha L, Linhares MBM. Temperamento de crianças e diferenças de gênero. Paidéia. 2013;23(54):63-72. DOI: http://dx.doi.org/10.1590/1982-432723 54201308.

25. Rothbart MK, Derryberry D. Development of individual differences in temperament. In: Lamb ME, Brown AL. Advances in Developmental Psychology. Hillsdale: Erlbaum; 1981; p. 37-86.

26. Rothbart MK. Commentary: differentiated measures of temperament and multiple pathways to childhood disorders. J Clin Child Adolesc Psychol. 2004; 33(1): 82-7. DOI: http:/ /dx.doi.org/10.1207/S15374424JCCP3301_8.

27. Rueda MR, Posner MI, Rothbart MK. Attentional Control and Self-Regulation. In: Vohs KD, Baumeister RF. Handbook of Self-Regulation: Research, Theory and Applications. New York: The Guilford Press; 2011; p. 284-99.

28. Rothbart MK. The Struture of Temperament. In: Rothbart MK. Becoming Who We Are. New York: The Guilford Press; 2011; p. 33-61.

29. Feldman R. The development of regulatory functions from birth to 5 years: insights from premature infants. Child Dev. 2009;80(2):54461.DOI: http://dx.doi.org/10.1111/j.1467624.2009.01278.x.

30. Klein VC, Gaspardo CM, Martinez FE, Grunau $R E$, Linhares MBM. Pain and distress reactivity and recovery as early predictors of temperament in toddlers born preterm. Early Hum Dev. 2009; 85(9):569-76. DOI: http:// dx.doi.org/10.1016/ j.earlhumdev.2009. 06.001.

31. Cockburn F, Cooke RWI, Gamsu HR, Greenough A, Hopkins A, Mcintosh $\mathrm{N}$, et al. The CRIB (Clinical Risk Index for Babies) score: a tool for assessing initial neonatal risk and comparing performance of neonatal intensive care units. Lancet. 1993;342(8865):193-8. DOI: http:// dx.doi.org/10.1016/0140-6736(93)92296-6.

32. Johnston $C$, Filion $F$, Snider L, Majnemer A, Limperopoulos C, Walker C, et al. Routine sucrose analgesia during the first week of life in neonates younger than 31 weeks' postconceptional age. Pediatrics. 2002; 110(3): 523-8. DOI: http://dx.doi.org/10.1542/ peds.110.3.523.

33. Putnam SP, Gartstein MA, Rothbart MK. Measurement of fine-grained aspects of toddler temperament: The Early Childhood Behavior Questionnaire. Infant Behav Dev. 2006; 29(3): 386-401. DOI: http://dx.doi.org/10.1016/ j.infbeh.2006.01.004.

34. Klein VC. Reatividade à dor, temperamento e comportamento na trajetória de desenvolvimento de neonatos pré-termo até a fase préescolar. Tese (Doutorado) - Faculdade de 
Medicina de Ribeirão Preto da Universidade de São Paulo. Ribeirão Preto: 2009.

35. Associação Brasileira de Empresas de Pesquisa. Critério de Classificação Econômica Brasil. [cited 2013 aug 26] Available from: http:// www.abep.org/novo/CMS/Utils/FileGenerate. ashx? id $=46$

36. Achenbach TM, Rescorla LA. Child Behavior Checklist for Ages $1 \frac{1}{2}-5$. Burlington: ASEBA; 2000.

37. Blair C. Early intervention for low birth weight, preterm infants: the role of negative emotionality in the specification of effects. Dev Psychopathol. 2002;14(2):311-32. DOI: http:/ /dx.doi.org/10.1017/S0954579402002079.

38. Calkins S. Regulatory competence and early disruptive behavior problems: the role of physiological regulation. In: Olson SL, Sameroff AJ. Biopsychosocial regulatory processes in the development of childhood behavioral problems. New York: Cambridge University Press; 2009; p. 86-107.

39. Rothbart MK, Bates JE. Temperament. In: Damon W, Lerner RM, Eisenberg N. Handbook of child psychology: social, emotional and personality development. New York: John Wiley and Sons; 2006; p. 99-165.

40. Muris $P$, Ollendick TH. The role of temperament in the etiology of child psychopathology. Clin Child Fam Psychol Rev. 2005;8(4):271-89. DOI: http://dx.doi.org/10.1007/s10567-005-8809-y.

41. Gunnar MR, Sebanc AM, Tout K, Donzella B, van-Dulmen $\mathrm{MMH}$. Peer rejection,temperament, and cortisol activity in preschoolers. Dev Psychobiol. 2003;43(4):346-58.

42. Wachs TD. Contributions of temperament to buffering and sensitization processes in children's development. Ann N Y Acad
Sci.2006;1094:28-39. DOI: http://dx.doi.org/ 10.1196/annals.1376.004.

43. Putnam SP, Jones LB, Rothbart MK. The Early Childhood Behavior Questionnaire: development, psychometrics, factor, structure, and relations with behavior problems. In: International Conference on Infant Studies. Canada: Ontario; 2002.

44. Zhong J, Qian MA. Study of development and validation of Chinese Mood Adjective Checklist. Chinese J Clinical Psychol. 2005;(1):8-13. DOI: http://caod.oriprobe.com/articles/8564855A_ Study_of_Development_andalidation_of_Chinese_ Mood_Adjective_Check_.htm.

45. Sroufe LAE, Egeland B, Carlson EA, Collins WAA. The development of the person. The Minnesota study of risk and adaptation from birth to adulthood. New York: The Guilford Press; 2005.

46. Rothbart MK, Chew K, Gartstein, MA.Assessment of temperament in earlydevelopment. In: Singer L, Zeskind PS. Biobehavioral assessment of the infant. New York: Guilford; 2001; p.190-208.

47. Rothbart MK, Hwang J. Measuring infanttemperament. Infant Behav Dev. 2002;25:113-16. DOI: http://dx.doi.org/ 10.1016/S0163-6383(02)00109-1.

48. Putnam SP, Ellis LK, Rothbart MK. The structure of temperament from infancy through adolescence. In: Eliasz A, Angleitner A. Advances in Research on Temperament. Germany: Pabst Scientific; 2001; p.165-82.

49. Als H. Program Guide - Newborn Individualized Developmental Care and Assessment Program (NIDCAP): an education and training program and health care professionals. Boston: Children's Medical Center Corporation; 2002.

\section{Resumo}

Introdução: o nascimento prematuro constitui-se em fator de risco para problemas de desenvolvimento e comportamento da criança. Objetivo: verificar se características clínicas neonatais de recém-nascidos pré-termo, bem como o temperamento avaliado na primeira infância são preditores de problemas de comportamento durante a fase pré-escolar. Método: vinte e uma crianças nascidas pré-termo com muito baixo peso foram avaliadas longitudinalmente em três idades diferentes: no período neonatal, durante a primeira infância, e na fase pré-escolar. Os prontuários médicos foram revisados para avaliar as características clínicas das crianças durante a fase neonatal. As mães responderam o Early Childhood Behavior Questionnaire para avaliação do temperamento na primeira infância e o Child Behavior Checklist-1.5-5 para avaliação dos problemas de comportamento das crianças na fase pré-escolar. Resultados: muito baixo peso ao nascimento, associado às características do temperamento da criança, na primeira infância, foram preditores de problemas de comportamento na fase pré-escolar, em crianças nascidas pré-termo. Altos níveis de antecipação positiva, bem como baixos níveis de controle inibitório, aumentaram o risco de as crianças apresentarem problemas de comportamento do tipo externalizantes. Por outro lado, altos níveis de ativação motora ampla e fina aumentaram o risco de as crianças apresentarem problemas de comportamento do tipo internalizantes. Conclusão: a prematuridade, associada a indicadores do temperamento com baixa autorregulação, caracterizam-se como condições de múltiplo risco para problemas de comportamento em crianças na fase pré-escolar.

Palavras-chave: prematuridade, temperamento, comportamento. 